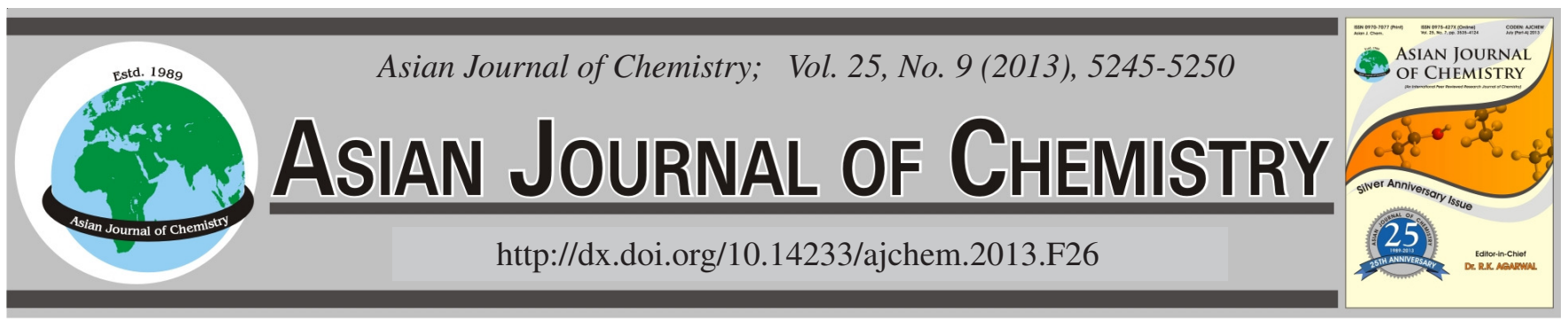

\title{
Investigation of Reaction Rate of Bis(triethoxysilylpropyl)tetrasulphide in Silica-Filled Compound Using Pyrolysis-Gas Chromatography/Mass Spectrometry $\dagger$
}

\author{
Sung-Ho HA*, Sung-Woo KIM and Ho-Kyun JEONG
}

NEXEN Tyre Corporation R\&D Center, Kyungnam 626-230, Republic of Korea

*Corresponding author: Fax: +82 55 3705366; Tel: +82 55 3704871; E-mail: saintsky@ nexentire.co.kr

Pyrolysis-gas chromatography/mass spectrometry (Py-GC/MS) was used to examine the reaction rate of bis(triethoxysilylpropyl)tetrasulphide in silica-filled rubber. The major pyrolysis product of bis(triethoxysilylpropyl)tetrasulphide, which is used as a silane coupling agent, was found to be an allyltriethoxysilane. Allyltriethoxysilane was also detected in the uncured silica-filled styrenebutadiene rubber compound with bis(triethoxysilylpropyl)tetrasulphide. To investigate the silica/silane reaction rate, the allytriethoxysilane content was used as an indicator and quantified by the relative peak area ratio of allytriethoxysilane/styrene. Styrene is a pyrolysis product of styrene-butadiene rubber. The results revealed an increase in reaction rate with increasing allytriethoxysilane content. Overall, pyrolysisgas chromatography/mass spectrometry can be used to estimate the reaction rate of the silica/silane system.

Key Words: Silane coupling agent, Bis(triethoxysilylpropyl)tetrasulphide, Silica, Pyrolysis-gas chromatography/mass spectrometry. |

ᄂ - - - - - - - - - - - - - - - - - - - - - - - - - - -

\section{INTRODUCTION}

Silica is an important reinforcing agent (filler) in a rubber compound together with carbon black ${ }^{1-5}$. On the other hand, silica-filled compounds can cause poor dispersion because of the strong filler-filler interaction by hydrogen bonding between the hydroxyl groups on the surface of silica. In addition, the formation of chemical bonds between hydrophilic silica and hydrophobic rubber are difficult ${ }^{6,7}$. These phenomena are improved by the addition of organosilane as a silane coupling agent in rubber compound ${ }^{8,9}$. The use of silica in combination with a silane coupling agent, which is often called the silica/ silane system, in the tyre industry improved the tyre performance such as the wet traction and rolling resistance, etc. ${ }^{10-12}$.

The silica/saline system has been studied extensively $y^{3,13-16}$. Each of the active groups of the silane coupling agent is bonded between rubber and silica under certain conditions. Bis(triethoxysilylpropyl)tetrasulphide (TESPT) is used widely as a silane coupling agent in the tyre industry. The triethoxysilyl groups of TESPT react with the silanol groups on the silica surface during mixing, and the sulfur of TESPT reacts with the rubber chain during curing. Reuvekamp et al. ${ }^{17}$ examined the effects of time and temperature on the reaction of TESPT silane coupling agent during mixing. As discussed by Reuvekamp et al. ${ }^{17}$, a temperature of at least $130{ }^{\circ} \mathrm{C}$ is necessary to ensure the reaction between the coupling agent and silica, whereas the coupling agent begins to react with the rubber or donate sulfur at temperatures $>160{ }^{\circ} \mathrm{C}$. Hunsche and Goerl et al. ${ }^{18,19}$ reported a horizontal reaction model consisting of two main reactions known as primary and secondary reactions in the silica/silane system using CP/MAS solid state NMR spectroscopy. Therefore, rubber manufacturers need to control the chemical reaction during the mixing process to take advantage of the silica/silane system.

Pyrolysis-gas chromatography/mass spectrometry (Py-GC/MS) has been used for several decades to analyze polymer and polymer additives ${ }^{20-23}$. One of the advantages of this technique is that all polymer and additive compositions can be investigated without a pretreatment, providing important compositional and structural information ${ }^{24}$.

This study investigated the reaction rate of TESPT in a silica-filled compound using pyrolysis-GC/MS. To establish the validity of pyrolysis-GC/MS, uncured silica-filled styrenebutadiene rubber (SBR) compounds were investigated under a range of compounding conditions.

\section{EXPERIMENTAL}

Silica-filled SBR compounds were prepared. The filled compounds were made from SBR, silica, silane coupling agent, cure activator and curatives. SBR 1783 with a styrene content 
of $23.5 \mathrm{wt}$ \% was used as the SBR. Ultrasil 7000GR was employed as the silica compound with a content of $50 \mathrm{phr}$ in the compound. Bis(triethoxysilylpropyl)tetrasulphide was used as the silane coupling agent. Bis(triethoxysilylpropyl)tetrasulphide with a $0.0-14.0$ wt.\% silica content was then added. Zinc oxide and stearic acid were used as the cure activator. Sulfur, Ncyclohexyl-2-benzothiazole sulfenamide (CBS) and diphenyl guanidine (DPG) were used as the vulcanizing agent and accelerator, respectively. The formulation is listed in Table-1.

\begin{tabular}{lc}
\multicolumn{2}{c}{ TABLE-1 } \\
FORMULATION OF THE FILLED SBR COMPOUND \\
\hline \multicolumn{1}{c}{ Component } & phr \\
\hline SBR $1783^{\mathrm{a}}$ & 137.5 \\
Silica & 50.0 \\
TESPT & Various \\
Stearic acid & 2.0 \\
ZnO & 3.0 \\
Sulfur & 1.5 \\
CBS & 1.5 \\
DPG & 1.0 \\
\hline
\end{tabular}

${ }^{a}$ SBR 1783: $27.3 \%$ oil-extended styrene-butadiene rubber.

Compounding: To measure the reaction rate of silica and the silane coupling agent, compounding was performed under a range of mixing conditions. Mixing was performed in a Banbury type mixer. The master batch (MB) and final mixing (FM) stages were carried out at a rotor speed of 76 and 50 rpm, respectively. The initial temperatures of the mixer were $110^{\circ} \mathrm{C}$ and $70{ }^{\circ} \mathrm{C}$ for the master batch and final mixing steps, respectively. The mixing times of master batch ranged from 0.0 to 420 seconds. The dumping temperatures of master batch were $130,150,170$ and $190^{\circ} \mathrm{C}$, respectively. The vulcanizates were prepared by curing at $165^{\circ} \mathrm{C}$ for $20 \mathrm{~min}$.

Bound rubber: The bound rubber contents (BdR\%) were determined by extraction with toluene at room temperature for 7 days using the uncured SBR-filled compound. The sample weight for the extracting experiment was $c a .0 .2 \mathrm{~g}$. The weights of the sample before and after extraction were measured and the bound rubber contents were calculated as

$$
\operatorname{BdR}(\%)=\left(\mathrm{W}_{\mathrm{fg}}-\mathrm{W} \times \mathrm{m}_{\mathrm{f}} / \mathrm{m}_{\mathrm{t}}\right) /\left(\mathrm{W} \times \mathrm{m}_{\mathrm{p}} / \mathrm{m}_{\mathrm{t}}\right) \times 100
$$

where $\mathrm{W}_{\mathrm{fg}}$ is the weight of the filler and gel, $\mathrm{W}$ is the weight of the specimen, and $\mathrm{m}_{\mathrm{f}}$ is the $\mathrm{phr}$ of the filler and inorganic ingredient in the compound. $\mathrm{m}_{\mathrm{p}}$ is the phr of the polymer in the compound and $\mathrm{m}_{\mathrm{t}}$ is the total phr of the compound. The experiment was carried out three times and the mean was used for further analysis.

Crosslink density: The crosslink densities of the samples (cured SBR-filled compounds) were measured using the swelling method. The organic additives in the samples were removed by extraction with tetrahydrofuran (THF) and $n$-hexane for 2 and 1 day, respectively, followed by drying in a vacuum oven for 1 day. After the weights of the dried samples were measured, they were swollen in toluene for 2 days. The weights of the swollen samples were then measured. The swelling ratio (Q) was calculated using the equation:

$$
\mathrm{Q}=\left(\mathrm{W}_{\mathrm{s}}-\mathrm{W}_{\mathrm{u}}\right) / \mathrm{W}_{\mathrm{u}}
$$

where $\mathrm{W}_{\mathrm{s}}$ and $\mathrm{W}_{\mathrm{u}}$ are the weights of the swollen and dried samples. The reciprocal swelling ratio (1/Q) was used as the apparent crosslink density ${ }^{25}$. The experiment was carried out three times and averaged.

Pyrolysis-gas chromatography/mass spectrometry (PyGC/MS): The pyrolysis-GC/MS experiments were carried out on a JCI-22 Curie point pyrolyzer (JAI Co.) coupled to an Agilent 7890 gas chromatograph equipped with an Agilent 5975C series GC/MSD. Pyrolysis was carried out at $590{ }^{\circ} \mathrm{C}$ for $5 \mathrm{~s}$. The GC column was a DB-5MS fused silica capillary column and the oven temperature was held initially at $50^{\circ} \mathrm{C}$ for $2 \mathrm{~min}$, then increased to $60^{\circ} \mathrm{C}$ at $5^{\circ} \mathrm{C} / \mathrm{min}$, to $120^{\circ} \mathrm{C}$ at $10^{\circ} \mathrm{C} / \mathrm{min}$ and to $180^{\circ} \mathrm{C}$ at $30^{\circ} \mathrm{C} / \mathrm{min}$. The mass spectra were recorded at an electron impact ionization energy of $70 \mathrm{eV}$. Table-2 lists the instrument conditions. The pyrolysis-GC/MS experiment was

\begin{tabular}{|c|c|}
\hline \multicolumn{2}{|c|}{$\begin{array}{c}\text { TABLE-2 } \\
\text { PYROLYSIS-GC/MS INSTRUMENT CONDITIONS }\end{array}$} \\
\hline \multicolumn{2}{|l|}{ Pyrolyzer conditions } \\
\hline Sample loading & About $0.5 \mathrm{mg}$ \\
\hline Pyrolysis temperature & $590^{\circ} \mathrm{C}$ \\
\hline Pyrolysis time & $5 \mathrm{~s}$ \\
\hline \multicolumn{2}{|c|}{ Gas chromatograph conditions } \\
\hline Column & $\mathrm{J} \& \mathrm{~W}$ DB-5, $30 \mathrm{~m} \times 0.25 \mathrm{~mm} \times 0.25 \mu \mathrm{m}$ \\
\hline Inlet temperature & $280^{\circ} \mathrm{C}$ \\
\hline Carrier gas & Helium \\
\hline Injection mode & Split 50:1 \\
\hline Oven & $\begin{array}{l}\left.50^{\circ} \mathrm{C} \text { (hold } 2 \mathrm{~min}\right), 60^{\circ} \mathrm{C} \text { at } 5^{\circ} \mathrm{C} / \mathrm{min} \text {, } \\
120^{\circ} \mathrm{C} \text { at } 10^{\circ} \mathrm{C} / \mathrm{min} \text {, and } 180^{\circ} \mathrm{C} \text { at } \\
30^{\circ} \mathrm{C} / \mathrm{min}\end{array}$ \\
\hline \multicolumn{2}{|c|}{ Mass spectrometer conditions } \\
\hline Mass temp & $230^{\circ} \mathrm{C}$ (Source), $150^{\circ} \mathrm{C}($ Quad $)$ \\
\hline Transfer line & $250^{\circ} \mathrm{C}$ \\
\hline MS & Electron ionization, SIM and Scan mode \\
\hline
\end{tabular}
carried out three times and the mean was used for further analysis.

\section{RESULTS AND DISCUSSION}

Pyrolysis-GC/MS analysis was performed to identify a characteristic peak of TESPT. Fig. 1(a) presents the pyrogram of TESPT. Bis(triethoxysilylpropyl)tetrasulphide showed a major pyrolysis product at $10.55 \mathrm{~min}$. This was assigned to allyltriethoxysilane (ATES) using the NIST mass library program. Allyltriethoxysilane was detected because the triethoxy groups of TESPT do not react with the silica surface. Therefore, ATES was regarded as characteristic pyrolyzate of unreacted TESPT. For more accurate identification, an allyltriethoxysilane agent (Aldrich) was analyzed by GC/MS without a pyrolysis process (shown in Fig. 1(b)). The main peaks of TESPT and ATES appeared at the same retention time and had an identical mass spectrum. Therefore, the characteristic peak of TESPT was identified as ATES. The formation process of ATES was expected due to cleavage of the relatively weak $\mathrm{C}-\mathrm{S}$ bonds and/or the S-S bond dissociation energy of TESPT during the pyrolysis process (Fig. 2).

Fig. 3 shows the pyrograms of each uncured silica filled SBR compound with/without TESPT. Py-GC/MS was performed in selected ion monitoring (SIM) mode to detect the peaks of only SBR and TESPT. The major pyrolysis products of SBR obtained from SIM mode were butadiene (2.72 min), C7species (5.65 $\mathrm{min})$, 4-vinylcyclohexene (6.98 $\mathrm{min}$ ) and styrene $(8.12 \mathrm{~min})^{26}$. The characteristic peak (above-mentioned ATES) of TESPT at $10.55 \mathrm{~min}$ appeared in the pyrogram of 


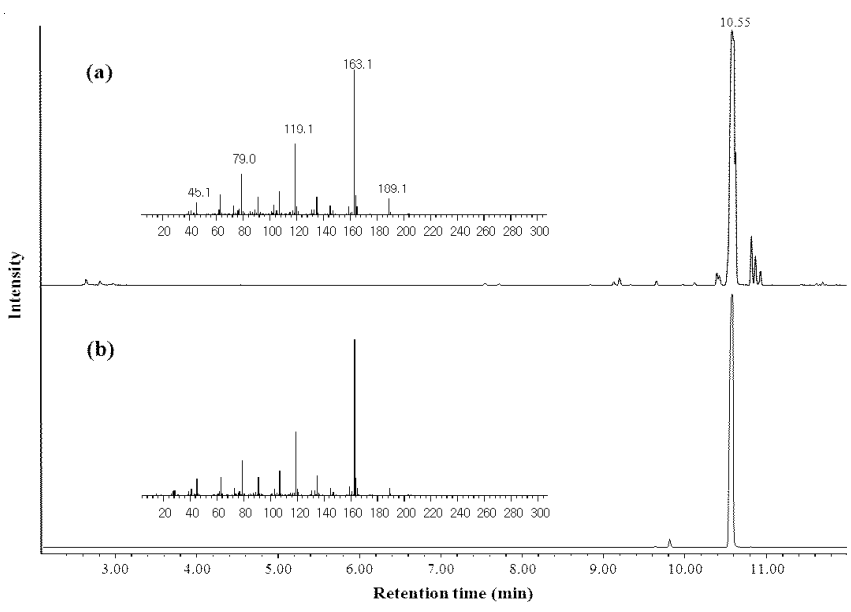

Fig. 1. Pyrolysis-GC/MS chromatogram and mass spectrum of TESPT (a) and ATES (b)

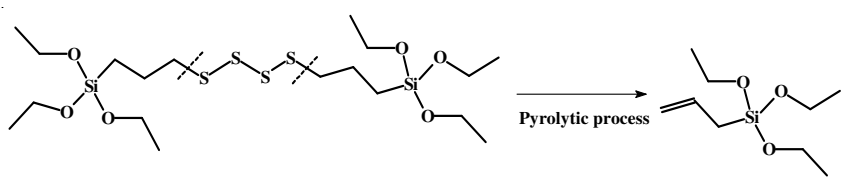

Fig. 2. Formation process of ATES from TESPT by pyrolysis-GC/MS

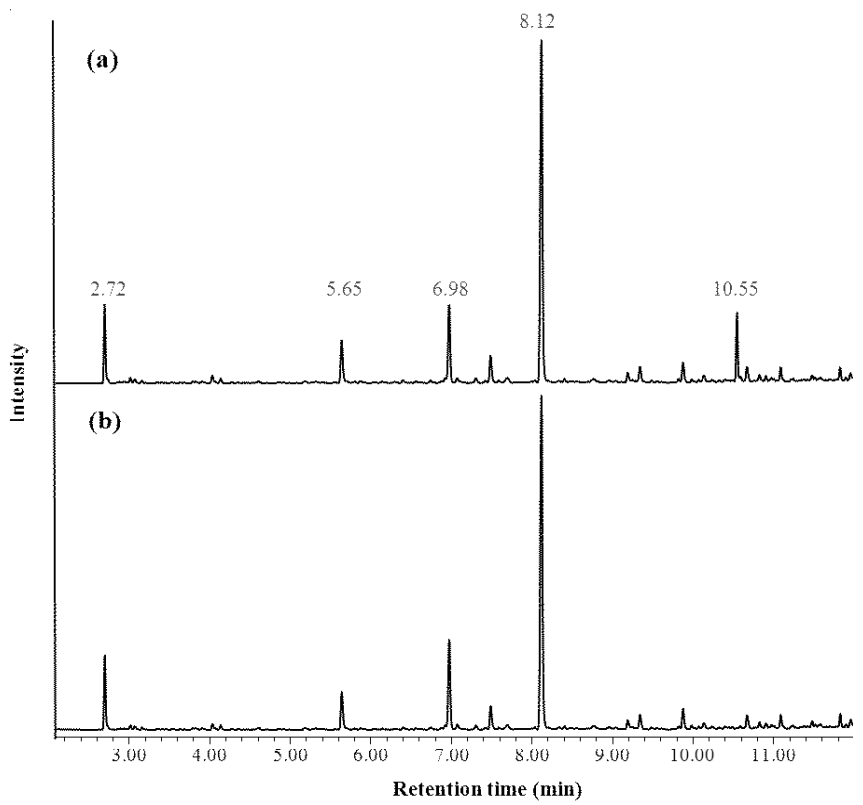

Fig. 3. Pyrolysis-GC/MS pyrograms of the uncured silica-filled SBR compound with TESPT (a) and without TESPT (b)

an uncured compound with TESPT [Fig. 3(a)]. On the other hand, ATES did not appear in the pyrogram of the uncured compound without TESPT (Fig. 3(b)). This indicates the presence of residual ethoxy groups of TESPT that did not react with the silica surface in uncured silica-filled compound with TESPT. The reaction rate of TESPT in the uncured compound can be measured by pyrolysis-GC/MS. Fig. 4 shows the TESPT bonding structure that can form ATES in silica-filled SBR compound. If there are many reactions between silica and TESPT, ATES should barely be detected by pyrolysis-GC/MS. Therefore, the reaction rate of TESPT and the amount of ATES might be inversely proportion to each other.

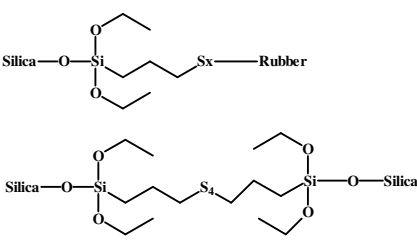

(a)
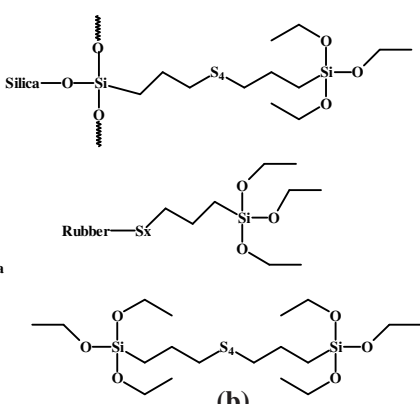

(b)
Fig. 4. Expected TESPT bonding structure for the formation of ATES (a) impracticable bonding structure (b) practicable bonding structure

To prove this, the uncured silica-filled SBR compounds under different mixing conditions were investigated by pyrolysis-GC/MS. A comparison of the peak area of SBR units revealed the styrene unit to have the lowest variation of all SBR units under different mixing conditions. This suggests that the styrene unit is almost unaffected by the mixing condition or additives. Table- 3 shows the variations of the peak area of the SBR unit measured by Py-GC/MS. The relative peak area of ATES and styrene in the uncured compounds was used to calculate the ATES content. The ATES content was calculated using the following equation:

$$
\mathrm{C}_{\text {ATES }}=\mathrm{P}_{\text {ATES }} / \mathrm{P}_{\text {Styrene }} \times 100
$$

where $\mathrm{C}_{\text {ATES }}$ is the relative ATES content, $\mathrm{P}_{\text {ATES }}$ is the peak area of ATES and $\mathrm{P}_{\text {Styrene }}$ is the peak area of styrene. A high $\mathrm{C}_{\text {ATES }}$ value indicates a low reaction rate of TESPT with the silica surface.

\begin{tabular}{ccccc}
\multicolumn{5}{c}{ TABLE-3 } \\
\multicolumn{5}{c}{$\begin{array}{c}\text { CHANGE IN PEAK AREA OF THE SBR } \\
\text { UNIT MEASURED BY Py-GC/MS }\end{array}$} \\
\hline $\begin{array}{c}\text { TESPT } \\
(\%)^{\mathrm{a}}\end{array}$ & Butadiene & $\begin{array}{c}\text { C7- } \\
\text { species }\end{array}$ & $\begin{array}{c}\text { 4-Vinyl } \\
\text { cyclohexene }\end{array}$ & Styrene \\
\hline \multicolumn{5}{c}{ Nor. area (\%) } \\
\hline 0.0 & 19.9 & 16.2 & 9.6 & 54.2 \\
2.0 & 19.3 & 17.4 & 9.5 & 53.8 \\
5.0 & 18.8 & 18.0 & 9.0 & 54.2 \\
8.0 & 18.3 & 17.8 & 8.9 & 55.0 \\
11.0 & 16.5 & 20.5 & 8.5 & 54.5 \\
14.0 & 18.0 & 18.2 & 8.2 & 55.7 \\
\hline \multicolumn{5}{c}{ Variation (\%) } \\
\hline 0.0 & 0.0 & 0.0 & 0.0 & 0.0 \\
2.0 & -3.1 & 7.4 & -1.8 & -0.8 \\
5.0 & -5.8 & 11.1 & -6.4 & -0.1 \\
8.0 & -8.1 & 9.5 & -7.6 & 1.5 \\
11.0 & -17.0 & 26.0 & -11.8 & 0.5 \\
14.0 & -9.7 & 12.0 & -15.4 & 2.7 \\
\hline${ }^{a} \%$ for TESPT on 100 parts silica filler.
\end{tabular}

Fig. 5 shows the results of pyrolysis-GC/MS analysis of the uncured silica-filled SBR compounds according to the TESPT concentration (0.0-14.0\%, on 100 parts silica). The ATES content increased with increasing TESPT concentration. On the other hand, the ATES content decreased slightly to a TESPT concentration of $c a .6 \%$ and then increased rapidly. This suggests that there is an optimal concentration on silica/ TESPT reaction and TESPT does not react with silica after reaching the optimal concentration. A similar result was reported by Hunsche et al. ${ }^{19}$ using CP/MAS NMR. 


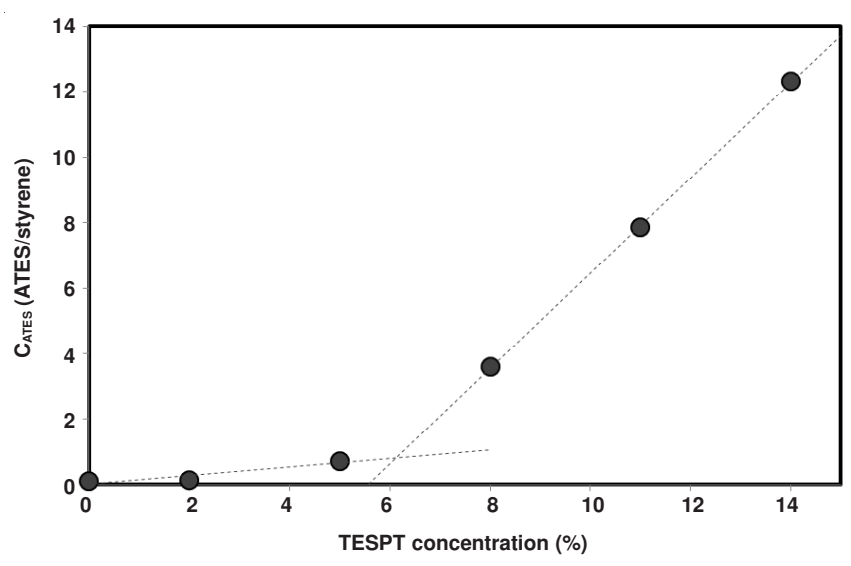

Fig. 5. ATES content of the uncured SBR-filled compounds as a function of the TESPT concentrations

Fig. 6 shows the results of pyrolysis-GC/MS analysis of uncured, silica-filled SBR compounds according to the changes in silica surface area. The TESPT concentration was $8 \%$ per 100 parts silica, and the BET (Brunauer-Emmett-Teller) surface area of silica was 115,175 and $235 \mathrm{~m}^{2} / \mathrm{g}$, respectively. The ATES content decreased with increasing silica surface area. In general, the silanol content of precipitated silica, which is used mainly in the tyre industry, is ca. 8-9 hydroxyl groups per $\mathrm{nm}^{2}\left(\mathrm{OH} / \mathrm{nm}^{2}\right)^{3}$. The increase in surface area can lead to an increase in hydroxyl groups. Therefore, the reaction site between TESPT and the silica surface is increased and the ethoxy groups of TESPT are decreased. The silica/TESPT reaction rate increased with increasing silica surface area.

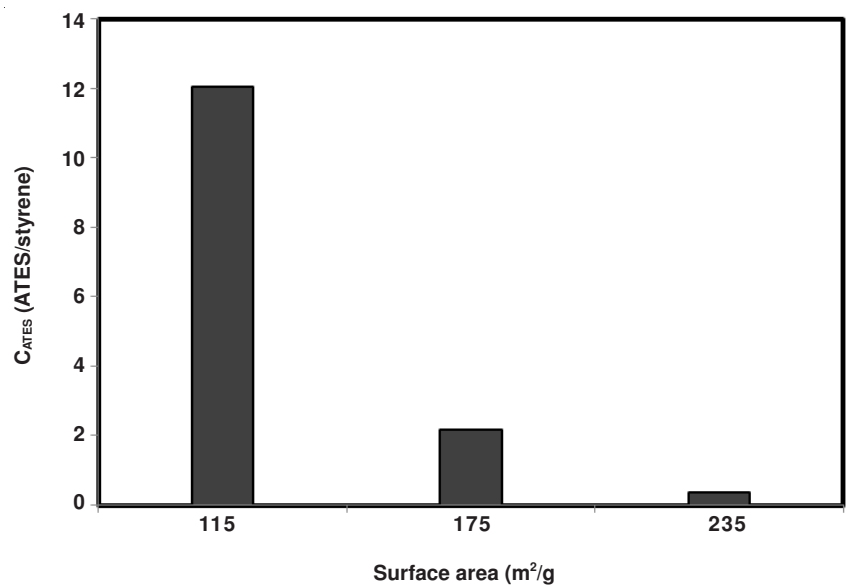

Fig. 6. ATES content of uncured SBR-filled compounds as a function of the silica surface area

Fig. 7 shows the results of the uncured silica filled SBR compounds at different mixing times in the master batch step. In this experiment, the mixing time ranged from 0.0 to $420 \mathrm{~s}$ in the master batch step. The mixing temperature remained constant at $145^{\circ} \mathrm{C}$. The ATES content decreased with increasing mixing time. At a mixing time $>300 \mathrm{~s}$, however, the downward trend was gentle and the ATES content reached a constant value. This suggests that most of the silica/TESPT reaction is in an equilibrium state after a certain mixing time. Therefore, the silica/TESPT reaction requires a sufficient mixing time to obtain a proper reaction rate.

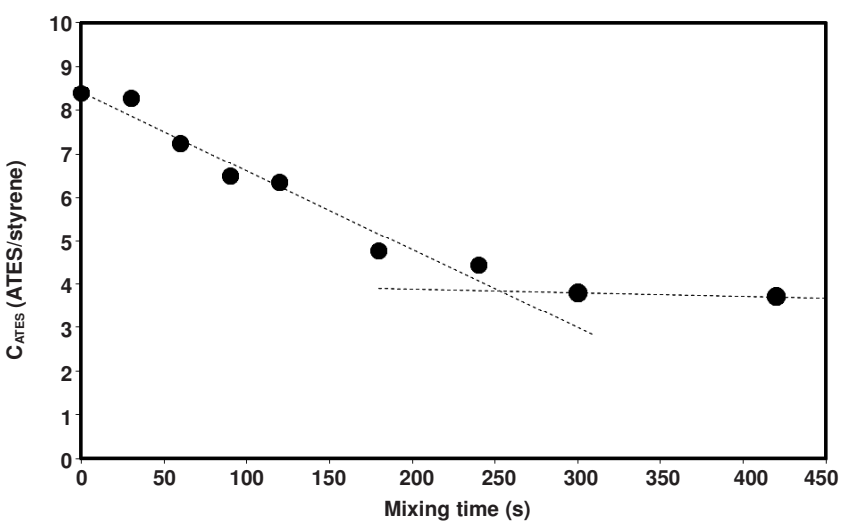

Fig. 7. ATES content of uncured SBR-filled compounds as a function of the mixing times

Fig. 8 shows the effect of the storage time on the silica/ TESPT reaction in uncured silica filled SBR compounds. Two samples were stored at room temperature for 7 and 30 days in open containers, respectively. These samples were analyzed three times. The samples stored for 30 days decreased by more than $50 \%$ compared to those for 7 days. This shows that the reaction between TESPT and silica in an uncured silica filled SBR compound continues at room temperature during the storage time, as suggested by Hunsche et al. ${ }^{19}$. Hunsche et al. reported that the ethoxy group of TESPT is removed continuously by hydrolysis with moisture in an ambient atmosphere.

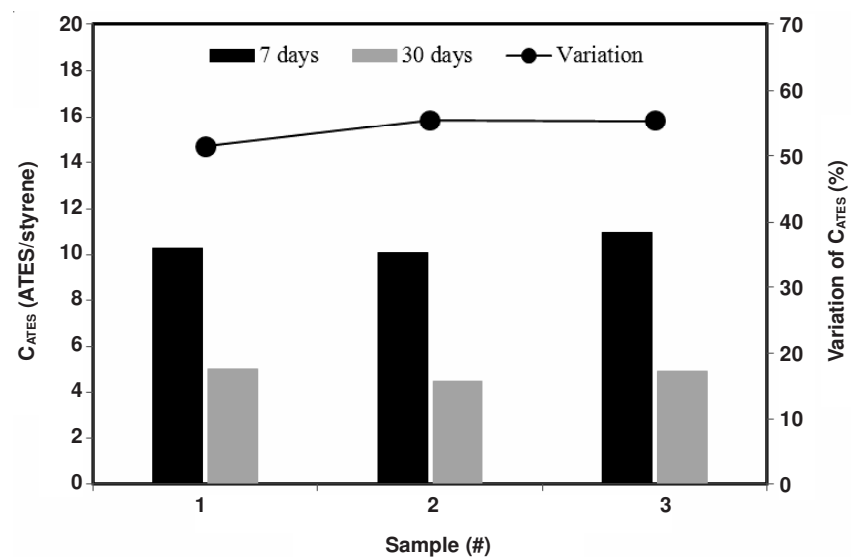

Fig. 8. ATES content of uncured SBR-filled compounds as a function of the storage time

Finally, the effect of the dumping temperature $(130,150$, 170 and $190{ }^{\circ} \mathrm{C}$ ) with a constant mixing time at the master batch step on silica/TESPT reaction was studied. The TESPT concentrations of each compound were 5,8 and $11 \%$ on silica 100 parts, respectively. Figs. 9 and 10 show the crosslink density and bound rubber contents according to the TESPT concentration and dumping temperature, respectively. When the TESPT concentration is equal, the crosslink density shows similar results regardless of the dumping temperature. On the other hand, the bound rubber contents increase with increasing TESPT concentration and dumping temperature. The bound rubber was increased not only by the silica/silane reaction but also by the curing process. The bound rubber contents increased because TESPT reacted as a sulfur donor with rubber at temperatures $>160{ }^{\circ} \mathrm{C}^{17}$. Therefore, the mixing temperature has a 


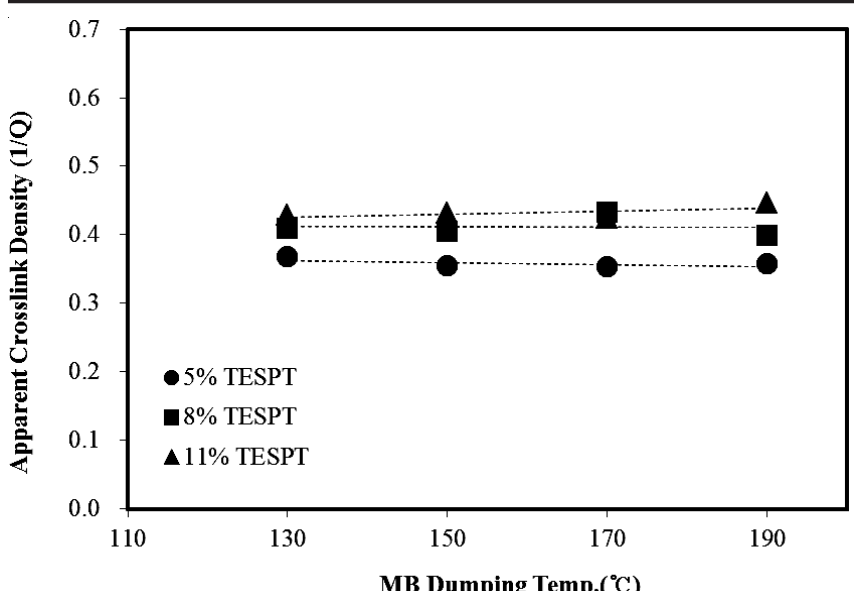

Fig. 9. Crosslink density of the uncured silica-filled SBR compounds as a function of the master batch (MB) dumping temperature

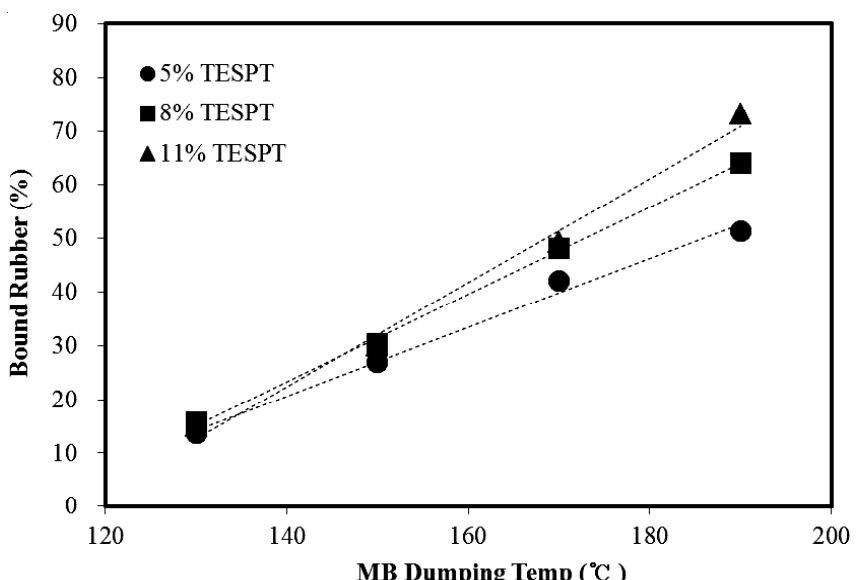

Fig. 10. Bound rubber content of the uncured silica-filled SBR compounds as a function of the master batch (MB) dumping temperature

significant effect on the bound rubber formation in a silicafilled compound. Allyltriethoxysilane should be detected in abundance at relatively low mixing temperatures and bound rubber contents. Fig. 11 shows the pyrolysis-GC/MS result of the bound rubber (BdR) and uncured compound. As expected, the ATES content at low temperatures was higher than that at high temperatures in both the uncured compound and bound rubber. The ATES contents of bound rubber showed a decreasing trend against the uncured compound because most of the TESPT reacted to produce bound rubber. The unbound polymer extracted by toluene in the bound rubber experiment was analyzed. Fig. 12 shows result of pyrolysis-GC/MS of the unbound polymer obtained as bound rubber experiment. The ATES was also detected in the unbound polymer and the resulting trend was similar to that of the uncured compound. This suggests that the TESPT, which did not react with the silica surface and/or formed a pendent group ${ }^{27}$ bonded to a rubber chain, can be extracted in the uncured compound. Because TESPT has fewer reactions with the silica surface and/or rubber chain at relatively low temperatures, the ATES content increases with increasing dumping temperature at the master batch step.

\section{Conclusion}

The pyrolysis-GC/MS technique was used to determine the reaction rate of TESPT in silica-filled SBR compound.

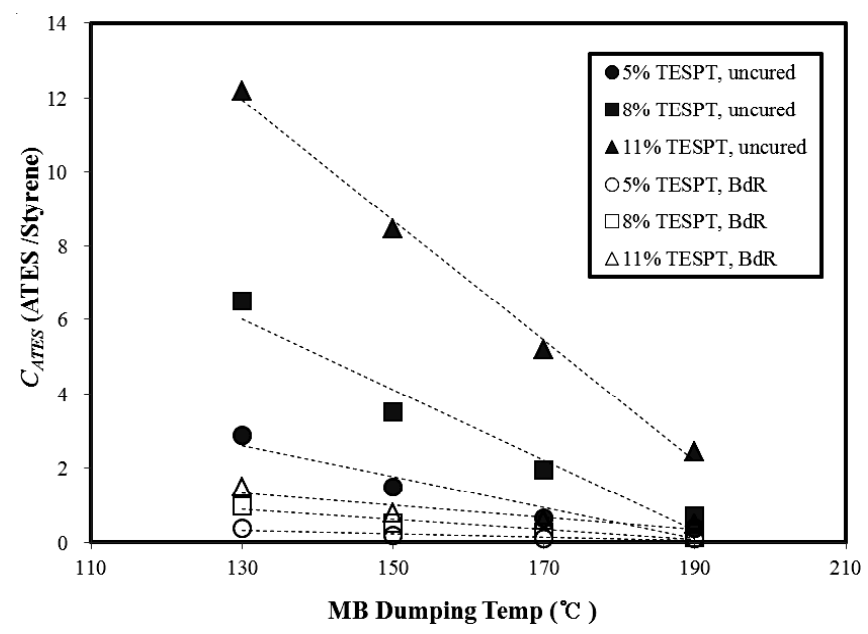

Fig. 11. ATES content of the uncured compound and bound rubber as a function of the master batch (MB) dumping temperature

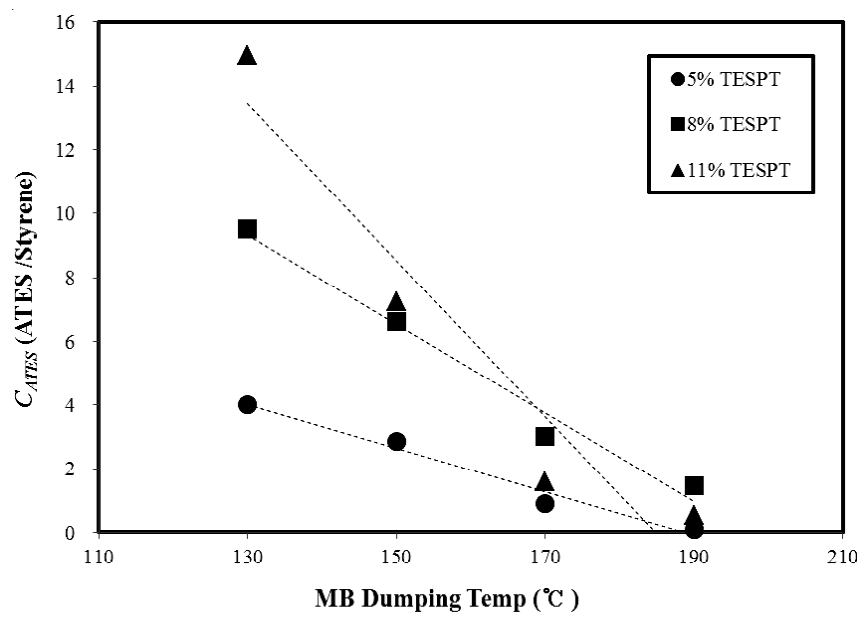

Fig. 12. ATES content of the extracted polymer during the bound rubber experiment

Allyltriethoxysilane was produced by the pyrolysis of TESPT, and was detected in the uncured compound. The relative ATES content was used to determine the reaction rate. The uncured compound under various mixing conditions was used to examine the effects of the TESPT concentration, mixing time, temperature, storage time and silica surface area. With increasing TESPT concentration in the compound, the ATES content increased slightly and then increased rapidly at some point. The ATES content decreased with increasing mixing time, temperature, storage time and silica surface area. In general, the reaction rate between TESPT and silica increases with increasing mixing time, temperature, storage time and silica surface area. The reaction rate of silica/silane and the ATES contents are inversely proportional to each other. Overall, by analyzing the ATES contents, it will be possible to examine the optimal mixing conditions for the silica-filled compound, as suggested by NMR or by measuring the physical properties.

\section{REFERENCES}

1. J.H. Bachmann, J.W. Sellers, M.P. Wagner and R.F. Wolf, Rubber Chem. Technol., 32, 1286 (1959).

2. B.B. Boonstra, H. Cochrane and E.M. Dánnenberg, Rubber Chem. Technol., 48, 558 (1975).

3. M.P. Wagner, Rubber Chem. Technol., 49, 703 (1976). 
4. A. Voet, J.C. Morawski and J.B. Donnet, Rubber Chem. Technol., 50, 342 (1977)

5. S. Wolff and M.-J. Wang, Rubber Chem. Technol., 65, 329 (1992).

6. Y. Li, M.J. Wang, T. Zhang, F. Zhang and X. Fu, Rubber Chem. Technol., 67, 693 (1994)

7. Y.-C. Ou, Z.-Z. Yu, A. Vidal and J.B. Donnet, Rubber Chem. Technol., 67, 834 (1994)

8. L.P. Ziemansky, C.A Pageno and M.W. Raney, Rubber World., 163, 53 (1970).

9. F. Thurn and S. Wolff, Kautsch Gummi Kunstst., 28, 733 (1975).

10. S. Wolff, Rubber Chem. Technol., 69, 325 (1996).

11. W.H. Waddell and L.R. Evans, Rubber Chem. Technol., 69, 377 (1996).

12. H. Mouri and K. Akutagawa, Rubber Chem. Technol., 72, 960 (1999).

13. A.S. Hashim, B. Azahari, Y. Ikeda and S. Kohjiya, Rubber Chem. Technol., 71, 289 (1998)

14. S.-S. Choi, Kor. Polym. J., 8, 285 (2000).

15. H.-D. Luginsland, J. Fröhlich and A. Wehmeier, Rubber Chem. Technol., 75, 563 (2002).

16. A. Blume and Köln, In Proceedings of Kautschuk Gummi Kunststoffe: Kinetics of the Silica-Silane Reaction, DE, April, pp. 38-44 (2011).
17. L.A.E.M. Reuvekamp, J.W. Brinke, P.J. Swaaij and J.W.M. Noordermeer, Rubber Chem. Technol., 75, 187 (2002).

18. U. Goerl, A. Hunsche, A. Mueller and H.G. Koban, Rubber Chem. Technol., 70, 608 (1997).

19. A. Hunsche, U. Goerl, A. Mueller, M. Knaack and Th. Goebel, Kautsch. Gummi Kunstst, 50, 881 (1997).

20. S.C. Moldoveanu, Analytical Pyrolysis of Synthetic Organic Polymers, Techniques and Instrumentation in Analytical Chemistry, 25, Elsevier Publication (2005).

21. S.W. Kim, G.S. Heo and G.H. Lee, J. Korean Chem. Soc., 41, 524 (1997).

22. K.D. Jansson, C.P. Zawodny and T.P. Wampler, J. Anal. Appl. Pyrol., 79, 353 (2007).

23. M. Herrera, G. Matuschek and A. Kettrup, J. Anal. Appl. Pyrol., 70, 35 (2003).

24. R. Rial-Otero, M. Galesio, J.-L. Capelo and J. Simal-Gandara, Chromatographia, 75, 339 (2009).

25. S.-S Choi and S.-H. Ha, Bull. Korean Chem. Soc., 27, 429 (2006).

26. S.-S. Choi, J. Anal. Appl. Pyrol., 62, 319 (2002).

27. S.-S. Choi, Polym. Test., 21, 201 (2002). 